\title{
A Novel Approach of Obtaining Theoritical Values in Selection of Cutting Fluid Attributes
}

\author{
E.S.Rama Ravi Kumar ${ }^{\text {A }}$;.Siva Ram Prasad ${ }^{\text {B }}$ \\ ${ }^{a}$ Dept. of Mathematics; V.R.Siddhartha Eng. College, Vijayawada, India, 520007 \\ ${ }^{b}$ Dept. of Mathematics; V.R.Siddhartha Eng. College, Vijayawada, India, 520007
}

\begin{abstract}
The Theoretical Values Are Defined In Novel Approach For Decision Making Based On Observed Values Of Chi Square Statistic. With These Values Of Theoretical Based On Expected, Decision Making Method Is Relatively New And Offers A Generic, Simple, Easy And Convenient Decision-Making Method That Involves Very Less Computation. The Method Lays Emphasis On Decision Making Methodology, Gives Much Attention To The Issues Of Identifying The Attributes And To Associating The Alternatives With The Attributes Etc. This Method Enables A More Critical Analyzing And Any Number Of Objective And Subjective Attributes Can Be Considered. The Measures Of The Attributes And Their Relative Importance Are Used Together To Rank The Alternatives And Hence Provide A Better Evaluation Of The Alternatives.
\end{abstract}

Key Words: Chi-Square Statistic, Decision Making, Machining Process Output Variables, GTMA.

\section{Introduction}

Much Heat Is Generated In Metal Cutting Operation Due To Plastic Deformation Of Work Materials, Friction At The Tool Chip Inter Face, And Friction Between The Clearance Face Of The Tool And The Work Piece. The Heat Generation Increases The Temperature Of Both The Work Piece And The Tool Point, Resulting In Decrease In Hardness And Hence Tool Life. The Machined Surface Will Also Be Less Smooth And The Possibility Of Built Up Edge Increases. So The Use Of The Cutting Fluid During A Machining Operation Is Very Essential. The Major Factors That Govern The Selection Of The Cutting Fluid Are (I) The Machining Process (Ii) Cutting Tool Material And (Iii) Work Piece Material. Other Factors Such As Compatibility With Machine Tool, Performance Requirement, Operator Interaction, Environment Friendliness And Economy Must Also Be Looked Into. A Few Researchers Such As Rowe (1982), Sun Et Al. (2001), Rao And Gandhi (2001) And Tan Et Al. (2002) Have Presented Some Mathematical Models For Cutting Fluid Selection. Rao (2004) Proposed The Application Of Graph Theory And The Matrix Approach And Fuzzy MADM Methods For Cutting Fluid Selection.

In This Paper We Describe The 'Chi-Square Statistic And Matrix Approach For Decision Making' Of A Cutting Fluid Selection In A Given Machining Application.

\section{Methodology Of $\mathrm{X}^{2}$ Statistic And Matrix Approach Method}

The Main Steps Are Given Below

Step (I): Identify The Pertinent Attributes And The Alternatives Involved In The Decision Making Problem Under Consideration. Obtain The Values Of The Attributes $\left(\mathrm{A}_{\mathrm{i}}\right)$ By Normalizing The Objective Data On The Basis Of Beneficial Attributes Is One Of Which Higher Attribute Value Is More Desirable For The Given Machining Operation, And A Non-Beneficial Attribute Is One Of Which The Lower Attribute Value Is Desirable.

Step (II): The Relative Importance $\left(\mathrm{A}_{\mathrm{Ij}}\right)$ Of Different Attributes Are Determined As Follows.

Construct A Pair Wise Comparison Matrix Using A Scale Of Relative Importance. An Attribute Compared With Itself Is Always Assigned The Value '1', So The Main Diagonal Entries Of The Pair Wise Comparison Matrix Are All ' 1 '. The Numbers 3, 5, 7 And 9 Correspond To The Verbal Judgments "Moderate Importance", "Strong Importance", "Very Strong Importance" And "Absolute Importance" (With 2, 4, 6 And 8 For Compromise Between Thasa Values). Assuming M Attributes, The Pair Wise Comparison Of Attribute 'I' With Attribute ' $J$ ' Yields A Square Matrix $B_{\mathrm{Mxm}}$ Where $\mathrm{A}_{\mathrm{Ij}}$ Denotes The Comparative Importance Of Attribute 'I' With Respect To Attribute ' $J$ '. In The Matrix, $A_{\mathrm{Ij}}=1$ When $\mathrm{I}=\mathrm{J}$ And $\mathrm{A}_{\mathrm{Ji}}=\frac{1}{\mathrm{~A}_{\mathrm{Ij}}}$. The Matrix Obtain In This Step Is Called 'Relative Importance Matrix'.

Step(III): The Normalized Matrix Obtained In Step (I) Is Normalization Of Attributes And The Normalized Data Is Called Observed Values $\left(\mathrm{O}_{\mathrm{i}}\right)$ And The Theoretical Values $\left(\mathrm{E}_{\mathrm{i}}\right)$ Are Obtained By Matrix Multiplication Of Matrix In Step (I) And Relative Importance Matrix In Step (Ii). The Values Of The Cutting Fluid Selection 
Index Are Calculated Using $X^{2}$ Statistic Formula $X_{I}^{2}=\frac{\sum\left(0_{I}-E_{I}\right)^{2}}{E_{I}}$ For Each Cutting Fluid.

Step(IV): Take A Final Decision, Keeping Practical Considerations In Mind. All Possible Constraints Likely To Be Experienced By The User Are Looked Into During This Stage. These Include Constraints Such As Availability Or Assured Supply, Management Constraints, Political Constraints, Economic Constraints, Environmental Constraints Etc. However Compromise May Be Made Infavour Of An Alternative With Higher Index.

Example - 1. (Table:1)Data Of Cutting Fluid Selection Attributes Of Example

\begin{tabular}{|c|c|c|c|c|c|c|c|c|}
\hline Cutting Fluid & Ww $(\mathrm{Mm})$ & Tf $(\mathrm{N})$ & $\mathrm{Gt}\left({ }^{\mathrm{c}} \mathrm{c}\right)$ & $\mathrm{Sr}(\mathrm{Mm})$ & $\mathrm{R}$ & $\mathrm{Th}$ & $\mathrm{Ep}$ & $\mathrm{S}$ \\
\hline 1 & 0.035 & 34.5 & 847 & 1.76 & $\mathrm{~L}$ & $\mathrm{~A}$ & $\mathrm{Aa}$ & $\mathrm{Aa}$ \\
2 & 0.027 & 36.8 & 834 & 1.68 & $\mathrm{~L}$ & $\mathrm{H}$ & $\mathrm{H}$ & $\mathrm{H}$ \\
3 & 0.037 & 38.6 & 808 & 2.40 & $\mathrm{Aa}$ & $\mathrm{Aa}$ & $\mathrm{Ba}$ & $\mathrm{A}$ \\
4 & 0.028 & 32.6 & 821 & 1.59 & $\mathrm{~A}$ & $\mathrm{Aa}$ & $\mathrm{Aa}$ & $\mathrm{Ba}$ \\
\hline
\end{tabular}

L: Low; Ba: Below Average; A: Average; Aa: Above Average; H: High

Ww: Wheel Wear; Tf: Tangential Force; Gt: Grinding Temperature; Sr: Surface Roughness; R: Recyclability; Th: Toxic Harm Rate; Ep: Environment Pollution Tendency; S: Stability.

The Decision Makers Can Appropriately Make Use Of Any Of The Eight Scales Suggested By Chen And Hwang (1992) For Converting The Linguistic Terms To Fuzzy Scores. Out Of These Scales, We Consider 11-Point Scale For Conversion Of Linguistic Terms Into Fuzzy Scores For X ${ }^{2}$ Statistic Based Decision Making Of Cutting Fluid Selection For A Given Machining Application.

Table 2: Objective Data Of Cutting Fluid Selection Attributes Of Example 1.

\begin{tabular}{|c|c|c|c|c|c|c|c|c|}
\hline Cutting Fluid & Ww & Tf & Gt & Sr & R & Th & Ep & S \\
\hline 1 & 0.035 & 34.5 & 847 & 1.76 & 0.335 & 0.500 & 0.590 & 0.590 \\
2 & 0.027 & 36.8 & 834 & 1.68 & 0.335 & 0.665 & 0.665 \\
3 & 0.037 & 38.6 & 808 & 2.40 & 0.590 & 0.410 & 0.410 \\
4 & 0.028 & 32.6 & 821 & 1.59 & 0.500 & 0.590 & 0.590 & 0.500 \\
\hline
\end{tabular}

In The Present Work The Attributes Considered Are Ww, Tf, Gt, Sr, R, Th, Ep And S As Given In The Problem. The Objective Values Of The Cutting Fluid Selection Attributes Which Are Given In Table 2 Are To Be Normalized. The Attributes R And S Are Beneficial, And Higher Values Are Desirable Values Of These Attributes Are Normalized. The Attributes Ww, Tf, Gt, Sr, Th And Ep Are Non Beneficial And Lower Values Are Desirable Values Of These Attributes Are Normalized, As Explained In Methodology.

The Values Of These Attributes For Different Cutting Fluids Are Normalized, And Given Table 3 In Respective Columns.

Table 3: Normalized Data Of Cutting Fluid Selection Attributes Of Example (1):

\begin{tabular}{|c|c|c|c|c|c|c|c|c|}
\hline Cf & Ww & Tf & Gt & Sr & R & Th & Ep & S \\
\hline 1 & 0.7714 & 0.9449 & 0.9539 & 0.9034 & 0.5678 & 1 & 0.6949 & 0.8872 \\
2 & 1 & 0.8859 & 0.9688 & 0.9464 & 0.5678 & 0.7519 & 0.6165 \\
3 & 0.7297 & 0.8445 & 1 & 0.6625 & 1 & 0.8475 & 1 \\
4 & 0.9643 & 1 & 0.9842 & 1 & 0.8475 & 0.8475 & 0.6949 & 0.7519 \\
\end{tabular}

Table 4: Matrix Of Relative Importance Of Different Attributes $\left(\mathrm{a}_{\mathrm{ij}}\right)$ :

$\begin{array}{ccccccccc} & \text { Ww } & \text { Tf } & \text { Gt } & \text { Sr } & \text { R } & \text { Th } & \text { Ep } & \text { S } \\ \text { Ww } & 1 & 5 & 3 & 5 & 5 & 3 & 3 & 4 \\ \text { Tf } & 1 / 5 & 1 & 1 / 3 & 1 & 2 & 1 / 2 & 1 / 2 & 2 \\ \text { Gt } & 1 / 3 & 3 & 1 & 3 & 3 & 2 & 2 & 3 \\ \text { Sr } & 1 / 5 & 1 & 1 / 3 & 1 & 2 & 1 / 2 & 1 / 2 & 2 \\ \text { R } & 1 / 5 & 1 / 2 & 1 / 3 & 1 / 2 & 1 & 1 / 3 & 1 / 3 & 1 \\ \text { Th } & 1 / 3 & 2 & 1 / 2 & 2 & 3 & 1 & 1 & 3 \\ \text { Ep } & 1 / 3 & 2 & 1 / 2 & 2 & 3 & 1 & 1 & 3 \\ \text { S } & 1 / 5 & 1 / 2 & 1 / 3 & 1 / 2 & 1 & 1 / 3 & 1 / 3 & 1\end{array}$

However, It May Be Added That The Above Assigned Values Are For Demonstration Purpose Only. By Matrix Multiplication Of Table 3 And Table 4, We Obtain Theoretical Values $E_{I}$ 'S And Tabular Values Of Table 3 Are Considered As Observed Values $\mathrm{O}_{\mathrm{I}}$ 'S. From These Values Of Cutting Fluids Normalized Attributes Matrix (Table 3) And Theoretical Values Of Different Attributes, Chi-Square Statistic Values Of The Cutting Fluid Selection Index Is Calculated For Each Cutting Fluid.

The Cutting Fluid Selection Index Values Of Different Cutting Fluids Are Given Below In Descending Order. Cutting Fluid 4: 72.996; Cutting Fluid 2: 71.137; Cutting Fluid 3: 68.051; Cutting Fluid 1: 68.049

From The Above Values Of The Cutting Fluid Selection Index, It Is Clear That The Cutting Fluid Designated As 4 Is The Best Choice Among The Cutting Fluids Considered For The Cylindrical Grinding Operation Under 
Given Conditions. The Next Choice Is Cutting Fluid 2 And The Cutting Fluid 1 Is The Last Choice. It May Be Observed That This Ranking Is Based Up On Simultaneous Consideration Of The Machining Process Output Variables On Which The Cutting Fluid Has Influence As Well As The Environmental Properties And Characteristics Of The Cutting Fluids.

Saw Method: The Cutting Fluid Selection Index Values Are Calculated, And Are Arranged In Descending Order.

Cutting Fluid 4: 0.8994; Cutting Fluid 2: 0.8775; Cutting Fluid 3: 0.8443; Cutting Fluid 1: 0.8413

From The Above Values Of The Cutting Fluid Selection Index, It Is Clear That The Cutting Fluid, Designated As 4 Is The Best Choice Among The Cutting Fluids Considered For The Cylindrical Grinding Operation Under The Given Conditions.

Wpm: The Following Ranking Of Cutting Fluids Is Obtained:

Cutting Fluid 4: 0.8884; Cutting Fluid 2: 0.8603; Cutting Fluid 3: 0.8332; Cutting Fluid 1: 0.8300

The Ranking Is The Same As That Obtained By Using The Saw Method.

Ahp And Its Versions: The Alternative Cutting Fluids Are Arranged In Descending Order Of The Cutting Fluid Selection Index. Cutting Fluid 4: 0.9027; Cutting Fluid 2: 0.8830; Cutting Fluid 3: 0.8444; Cutting Fluid 1: 0.8417. From The Above Values Of The Cutting Fluid Selection Index, It Is Clear That The Cutting Fluid Designated As 4 Is The Best Choice Among The Cutting Fluids Considered For The Cylindrical Grinding Operation Under The Given Conditions.

Topsis Method: The Alternative Cutting Fluids Are Arranged In Descending Order Of Their Cutting Fluid Selection Index. This Can Be Arranged As 4-2-3-1.

Modified Topsis Method: The Alternative Cutting Fluids Are Arranged In The Descending Order Of Their Cutting Fluid Selection Index. This Can Be Arranged As: 4-2-3-1.

Example - 2: The Results Of A Cylindrical Turning Test Are Presented In The Table 5. This Test Is Conducted For The Purpose Of Evaluation Of Most Common, Commercially Available Metal Cutting Fluids, Namely Water Soluble, Straight Mineral, Chlorinated And Sulfochlorinated Oils.

Table - 5: Data Of Cutting Fluid Alternatives Of Example 2

\begin{tabular}{|l|l|l|l|l|}
\hline Cutting Fluid & $\mathrm{F}_{\mathrm{c}}(\mathrm{N})$ & $\mathrm{F}_{\mathrm{t}}(\mathrm{N})$ & $\mathrm{Wl}(\mathrm{Mm} * 100)$ & $\mathrm{R}_{\mathrm{rms}}(\mathrm{Mm})$ \\
\hline Dry & 1324 & 725 & 7 & 9 \\
Water Soluble & 1082 & 485 & 16 & 7 \\
Straight Mineral Oil & 1098 & 516 & 8 & 4.7 \\
Chlorinated Oil & 1158 & 494 & 15 & 4.9 \\
Sulfochlorinated Oil & 962 & 393 & 6 & 8 \\
\hline
\end{tabular}

$\mathrm{F}_{\mathrm{c}}$ : Cutting Force; $\mathrm{F}_{\mathrm{t}}$ : Thrust Force; Wl: Wear Land; $\mathrm{R}_{\mathrm{rms}}$ : Processed Surface Roughness Expressed In Rms Value.

This Example Is Considered To Demonstrate Further The Application Of The " $\mathrm{X}^{2}$ Statistic Based Matrix Approach Method For Cutting Fluid Selection. In This Example The Attributes Considered Are Fc, Ft, Wl And Rrms. The Objective Values Of The Cutting Fluid Selection Attributes, Which Are Given In Table 5 Are To Be Normalized. All Four Attributes Are On Non-Beneficial Type, The Lower Values Are Desirable Values Of These Attributes Are Normalized As Explained In Example 1, And Are Given In Table-6 In The Respective Columns.

Table-6: Normalized Data Of Cutting Fluid Attributes Of Example-2

\begin{tabular}{|l|l|l|l|l|}
\hline Cutting Fluid & $\mathrm{F}_{\mathrm{c}}(\mathrm{N})$ & $\mathrm{F}_{\mathrm{t}}(\mathrm{N})$ & $\mathrm{Wl}(\mathrm{Mm} * 100)$ & $\mathrm{R}_{\mathrm{rms}}(\mathrm{Mm})$ \\
\hline Dry & 0.7251 & 0.5489 & 1 & 0.5222 \\
Water Soluble & 0.9074 & 0.8206 & 0.4375 & 0.6714 \\
Straight Mineral Oil & 0.8743 & 0.7713 & 0.8750 & 1 \\
Chlorinated Oil & 0.8290 & 0.8057 & 0.4667 & 0.9592 \\
Sulfochlorinated Oil & 1 & 1 & 1 & 0.5875 \\
\hline
\end{tabular}

Relative Importance Of Attributes $\left(\mathrm{A}_{\mathrm{ij}}\right)$ Is Assigned Values As Explained In Example 1. Let The Decision Maker Select The Following Assignments 
Table-7: Matrix Of Relative Importance Of Different Attributes $\left(\mathrm{A}_{\mathrm{ij}}\right)$

$\begin{array}{ccccc} & \mathrm{F}_{\mathrm{C}} & \mathrm{F}_{\mathrm{T}} & \mathrm{Wl} & \mathrm{R} \\ \mathrm{F}_{\mathrm{C}} & 1 & 5 & 3 & 5 \\ \mathrm{~F}_{\mathrm{T}} & 1 / 5 & 1 & 5 & 2 \\ \mathrm{Wl} & 1 / 3 & 1 / 5 & 1 & 3 \\ \mathrm{R} & 1 / 5 & 1 / 2 & 1 / 3 & 1\end{array}$

By Multiplication Of Table-6 And Table-7, We Obtain The Theoretical Values ( $\mathrm{E}_{\mathrm{i}}$ 's) And The Values Of Attributes In Table-6 Are Considered As Observed Values $\left(\mathrm{O}_{\mathrm{i}}\right.$ 's). From These Values Of Cutting Fluids Normalized Attributes Matrix (Table 6) And Theoretical Values Of Different Attributes, Chi-Square Statistic Values Of The Cutting Fluid Selection Index Is Calculated For Each Cutting Fluid. The Cutting Fluid Selection Index Values Of Different Cutting Fluids Are Given Below In Descending Order.

Sulfo-Chlorinated Oil: 21.5442; Straight Mineral Oil: 18.3278; Water Soluble: 17.9107; Chlorinated Oil: 16.9279; Dry: 15.3263

From The Above Values Of The Cutting Fluid Selection Index, It Is Clear That The Sulfo-Chlorinated Oil Is The Best Choice Among The Cutting Fluids Considered For The Cylindrical Turning Test Under Given Conditions. The Next Choice Is Straight Mineral Oil And Dry Is The Last Choice.

Saw Method: The Cutting Fluid Selection Index Values Are Calculated, And Are Arranged In Descending Order.

Sulfo-Chlorinated Oil: 0.9588; Straight Mineral Oil: 0.8561; Water Soluble: 0.7638; Chlorinated Oil: 0.7626; Dry: 0.7069. The Saw Method Also Suggests Sulfo-Chlorinated Oil As The First Choice For The Cylindrical Turning Operation Under The Given Conditions.

Wpm: The Following Ranking Of Cutting Fluids Is Obtained By Wpm Method.

Sulfo-Chlorinated Oil: 0.9482; Straight Mineral Oil:0.8536; Chlorinated Oil: 0.7435; Water Soluble: 0.7383; Dry: 0.6883. This Method Also Suggests Sulfo-Chlorinated Oil As The Right Choice In This Example.

Gtma: The Cutting Fluid Selection Index Values Of Different Cutting Fluids Are Given Below In Descending Order. Sulfo-Chlorinated Oil: 2.8871; Straight Mineral Oil: 2.8172; Chlorinated Oil: 2.1483; Water Soluble: 17.9107;; Dry: 15.3263. This Method Also Suggests Sulfo-Chlorinated Oil As The Best Choice In This Example.

Topsis Method: The Following Is The Descending Order Of Cutting Fluid Selection Index Values.

Sulfo-Chlorinated Oil: 0.7976; Straight Mineral Oil: 0.7933; Dry: 0.6502; Chlorinated Oil: 0.2979; Water Soluble: 0.2108; This Method Also Suggests Sulfo-Chlorinated Oil As The Best Choice. However The Water Soluble Fluid Is Shown As The Last Choice In This Example.

Modified Topsis Method: The Cutting Fluid Selection Index Values Of Different Cutting Fluids Are Given Below In Descending Order. Sulfo-Chlorinated Oil: 0.7892; Straight Mineral Oil: 0.7285; Chlorinated Oil: 0.4500; Dry: 0.4468; Water Soluble: 0.4084;. This Method Also Suggests Sulfo-Chlorinated Oil As The Best Choice In This Example.

\section{Conclusion}

The Chi-Square Statistic And Matrix Approach Based Decision Making Method In Which The Theoretical Values Are Obtained By New Formula And Offers A Generic, Simple, Easy And Convenient Decision-Making Method That Involves Very Less Computation. The Measures Of The Attributes And Their Relative Importance Are Used Together To Rank The Alternatives And Hence Provide A Better Evaluation Of The Alternatives.

\section{Acknowledgements:}

Special Thanks To : Dr. R Venkata Rao, Professor, Dept. Of Mechanical Engg., Svnit, Surat; Dr.B.D.C.N.Prasad, Dept. Of Computer Applications; P.V.P.S.I.T, Vijayawada.

\section{References}

[1]. Rao Rv (2004) Performance Evaluation Of Cutting Fluids For Green Manufacturing Using A Combined Multiple Attribute Decision Making Method. Internal Journal Of Environmentally Conscious Design And Manufacturing 12: 526 - 535

[2]. Rao Rv, Gandhi Op (2001) Digraph And Matrix Method For Selection, Identification And Comparison Of Metal Cutting Fluids. Proc. Ime, Journal Of Engineering Tribology 212:307-318

[3]. Rowe Gw (1982) Lubricant Testing For Grinding Operations. Wear 77:73-80

[4]. Sun J, Ge P, Zhenchang L (2001) Two-Grade Fuzzy Synthetic Decision-Making System With Use Of An Analytic Hierarchy Process For Performance Evaluation Of Grinding Fluids. Tribology International 34:683-688

[5]. Tan Xc, Liu F, Cao Hj, Zhang H (2002) A Decision-Making Framework Model Of Cutting Fluid Selection For Green Manufacturing And A Case Study. Journal Of Materials Processing Technology 129:467-470. 